\title{
Ecophysiological and ultrastructural characterisation of the circumpolar orange snow alga Sanguina aurantia compared to the cosmopolitan red snow alga Sanguina nivaloides (Chlorophyta)
}

\author{
Lenka Procházková ${ }^{1}$ (D) Daniel Remias ${ }^{2} \mathbb{D} \cdot$ Andreas Holzinger $^{3} \mathbb{D} \cdot$ Tomáš Rezanka $^{4}$ (D) Linda Nedbalová $^{1}$ (D)
}

Received: 18 June 2020 / Revised: 18 November 2020 / Accepted: 24 November 2020 / Published online: 11 December 2020

(C) The Author(s) 2020

\begin{abstract}
Red snow caused by spherical cysts can be found worldwide, while an orange snow phenomenon caused by spherical cells is restricted to (Sub-)Arctic climates. Both bloom types, occurring in the same localities at Svalbard, were compared ecophysiologically. Using a combination of molecular markers and light- and transmission electron microscopy, cells were identified as Sanguina nivaloides and Sanguina aurantia (Chlorophyceae). In search for reasons for a cosmopolitan vs. a more restricted distribution of these microbes, significant differences in fatty acid and pigment profiles of field samples were found. S. aurantia accumulated much lower levels of polyunsaturated fatty acids ( $21 \%$ vs. $48 \%$ of total fatty acids) and exhibited lower astaxanthin-to-chlorophyll- $a$ ratio (2-8 vs. 12-18). These compounds play an important role in adaptation to extreme conditions at the snow surface and within snow drifts. Accordingly, the performance of photosystem II showed that one third to nearly half of the photosynthetic active irradiation was sufficient in S. aurantia, compared to S. nivaloides, to become light saturated. Furthermore, formation of plastoglobules observed in S. nivaloides but missing in S. aurantia may contribute to photoprotection. The rapid light curves of the two species show to a certain extent the shade-adapted photosynthesis under the light conditions at Svalbard (high $\alpha$-value 0.16 vs. 0.11 , low saturation point $I_{\mathrm{k}} 59$ vs. 86). These results indicate significant physiological and ultrastructural differences of the two genetically closely related cryoflora species, but the reasons why S. aurantia has not been found at conditions outside (Sub-)Arctic climate types remain unknown.
\end{abstract}

Keywords Arctic · Green algae · Astaxanthin · Polyunsaturated fatty acid · Chlamydomonas nivalis · Cryoflora

\section{Introduction}

Melting summer snowfields in polar regions are habitats for diverse microbial communities, including photoautotrophs causing snow discolorations (Hisakawa et al. 2015; Davey et al. 2019). Blooms of these microalgae significantly decrease snow and glacial surface albedo due to their pigmentation, thus, accelerating melting processes additionally to global warming (Lutz et al. 2016; Stibal et al. 2020). Red snow caused by spherical cysts, traditionally addressed as "Chlamydomonas nivalis" (regardless of their true taxonomic affiliation within the Chlorophyta), is probably the most common type of snow algal bloom in the Arctic and elsewhere. It has been intensely studied in the past (Hoham and Remias 2020). To a lesser extent, orange snow containing spherical cysts was reported from the Arctic as well (Leya et al. 2004; Stibal et al. 2007; Kvíderová 2012; Spijkerman et al. 2012). Recently, the algae of the two bloom types were described as distinct species: Sanguina 
nivaloides causing red snow and Sanguina aurantia causing orange snow. These species are not only distinguishable by the resulting macroscopic snow colour but also show differences in average cell sizes and in the sequence of the molecular ITS2 rDNA marker (Procházková et al. 2019a). No strains of Sanguina are available in culture, and thus, the life cycles of these algae, which should include migrating flagellates, are unknown. Practically, snow packs are populated by immotile, robust cysts during summer (Müller et al. 1998).

To understand the ecophysiological adaptation of these extremophiles to their harsh environment, characteristics such as life cycles, pigment composition, ice-binding proteins, photosynthetic light preferences and fatty acid profiles have been studied (Leya 2013). The focus of such studies has been on red snow forming species in high alpine (Remias et al. 2005) or polar sites (Soto et al. 2020), or on taxa causing orange snow in mid-latitude mountainous regions (Procházková et al. 2019b). In contrast, data on $S$. aurantia, which causes orange blooms at (Sub-)Arctic climate, are scarce.

While the red S. nivaloides has not only a striking cosmopolitan distribution in polar but also non-polar, mountainous regions, the orange $S$. aurantia has mainly been found in (Sub-)Arctic regions (Segawa et al. 2018; Procházková et al. 2019a) and recently in the alpine zone of mid-latitude mountain ranges of Northern America (Cascade Mts, Rocky Mts; Brown et al. 2016; Procházková et al. 2019a; Brown and Tucker 2020), where a local sub-arctic climate prevails (type Dfc sensu Köppen-Geiger climate system; Peel et al. 2007). The reasons for these biogeographic differences are unknown. Consequently, the aim of this study was, to our knowledge, the first attempt to compare physiological and ultrastructural traits of Arctic field communities to further elucidate the biogeographical patterns within this group, in particular the restriction of $S$. aurantia to Sub-Arctic and Arctic climate types. This comparison was performed by means of light- and transmission electron microscopy, photosynthesis measurements, analysis of pigments and fatty acids in S. aurantia and S. nivaloides. At Svalbard, blooms of both snow algae occurred at different spots in the same valleys (six cases) or in close proximity to each other (two cases), which made this comparative survey possible under practically identical abiotic conditions.

\section{Material and methods}

\section{Sampling and snow characteristics}

In July 2018, orange and red booms of snow were investigated at Tverrdalen, Bjørndalen, Jaderinfjorden, Goosbukta and Laponia Halvøya, Svalbard, Norway (Fig. 1, Table 1).

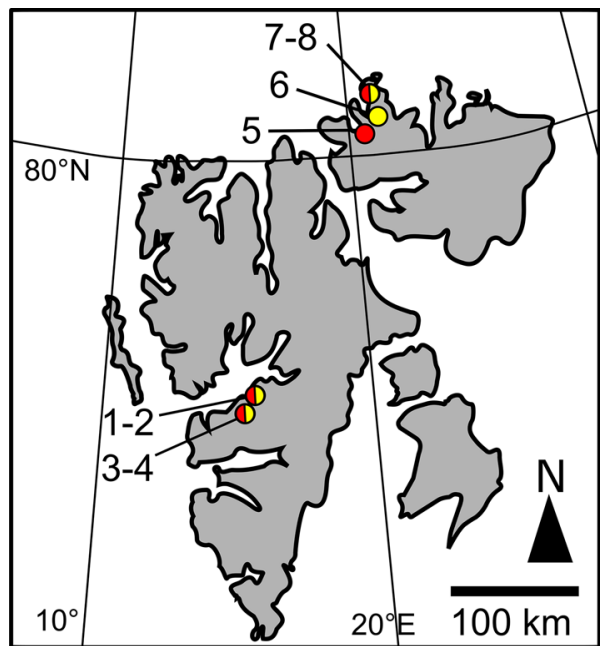

Fig. 1 Snow sampling locations of Sanguina nivaloides (red circle), Sanguina aurantia (yellow circle) and where both species were harvested (red-yellow circles) at the archipelago of Svalbard. The indicated sample numbers refer to Table 1

Virtually monospecific spots (one type of cells observed only) were intentionally selected based on light microscopy in the field to perform the polyphasic comparison between the two species, according to Procházková et al. (2019a). Four sites with a visible orange colouration and four sites with a red colouration were included in this study. Communities comprising a mixture of orange and red cells were excluded from the study. A surface snow layer of approximately $0.5 \mathrm{~cm}$ thickness was removed to reduce the content of dark snow detritus. Snow surface communities were harvested up to approximately $3 \mathrm{~cm}$ depth. Subsequently, orange and red samples were taken using a sterile steel scoop in 5-L buckets, 1 - $\mathrm{L}$ thermos bottles or $50-\mathrm{mL}$ centrifugation tubes, and transported the same day to the laboratory in Longyearbyen. The measurement of snow water equivalent (SWE; referred to as "snow water content" in Procházková et al. 2018a) was carried out as described previously (Procházková et al. 2018a). Prior to photosynthesis measurements, samples were melted gently at darkness overnight at $4-5{ }^{\circ} \mathrm{C}$. Electrical conductivity (EC) and $\mathrm{pH}$ of the meltwater were obtained with WTW Instruments (Cond 340i and Inolab, Germany). To show the prevailing climate in the sampling region around Longyearbyen during the snow melting season, minimum, maximum and mean daily air temperatures $\left({ }^{\circ} \mathrm{C}\right)$ were taken from a meteorological station in Adventdalen ( $78.202^{\circ} 15.828^{\circ}, 15 \mathrm{~m}$ a.s.l.).

\section{Light and transmission electron microscopy}

Morphological characterisation and determination of cell numbers per snow volume were performed by light microscopy (with an Olympus BX53 [equipped with an Olympus 
Table 1 Sampling locations of Sanguina species in Svalbard (Norway) with sample codes, collection date, sampling site, altitude (metres a.s.l.) and geographic position (GPS)

\begin{tabular}{|c|c|c|c|c|c|c|}
\hline Sample & Species & Date & Location & Altitude & GPS & $\mathrm{Nr}$. \\
\hline WP199 & S. aurantia & 3 July 18 & Tverrdalen near Longyearbyen & 293 & N78 11.777 E15 31.325 & (1) \\
\hline WP204 & S. nivaloides & 5 July 18 & Tverrdalen near Longyearbyen & 365 & N78 11.853 E15 31.012 & (2) \\
\hline WP206o & S. aurantia & 7 July 18 & Bjørndalen, west of Teltberget & 347 & N78 09.771 E15 18.315 & (3) \\
\hline WP206r & S. nivaloides & 7 July 18 & Bjørndalen, west of Teltberget & 347 & N78 09.771 E15 18.315 & (4) \\
\hline MN1 & S. nivaloides & 18 July 18 & Jaderinfjorden, Lady Franklinfjorden & 77 & N80 07.825 E19 32.203 & $(5)$ \\
\hline MN13 & S. aurantia & 19 July 18 & Goosbukta, Brennevinsfjorden & 6 & N80 12.501 E19 48.101 & $(6)$ \\
\hline MN21 & S. aurantia & 20 July 18 & Laponia Halvøya, Brennevinsfjorden & 127 & N80 23.841 E19 38.957 & (7) \\
\hline MN22 & S. nivaloides & 20 July 18 & Laponia Halvøya, Brennevinsfjorden & 127 & N80 23.841 E19 38.957 & (8) \\
\hline
\end{tabular}

The numbers in parentheses indicate point of origin in the map of Fig. 1

DP72 camera] or an Olympus BX43 [equipped with Nomarski Contrast and an Olympus DP27 camera or digital camera DXM 1200F (Nikon, Melville, NY, USA), using cellSens Entry Imaging Software]). Cell counting and transmission electron microscopy (TEM) of chemically fixed cells collected at WP199 and WP204 were carried out as previously described (Procházková et al. 2018a). The level of cyst maturation of less well-studied Sanguina aurantia ("young" vs. "mature") was inferred from cellular changes observed during earlier studies for Sanguina nivaloides (late spring vs. late summer sampling): first, the astaxanthin-to-chlorophyll$a$ ratio raised during the ongoing season (Remias et al. 2005) and second, changes in the extent of intracellular lipid body organisation (compare fig. 2B-D vs. fig. 2A in Procházková et al. 2019a).

\section{DNA extraction, PCR and molecular analysis}

DNA isolation was carried out with DNeasy Plant Mini Kit (Qiagen, Germany), as in Procházková et al. (2018a). The internal transcribed spacer region 2 (ITS2 rDNA) was amplified from DNA isolates by polymerase chain reaction (PCR) using existing primers SSU + LSU (Piercey-Normore and DePriest 2001) and ITS5 + ITS4 (White et al. 1990). Amplification reactions were described in Procházková et al. (2018a). PCR products were purified and sequenced using an Applied Biosystems-automated sequencer (ABI 3730xl) at Macrogen Europe (Amsterdam, Netherlands). The obtained ITS2 rDNA sequences were submitted to NCBI Nucleotide sequence database (accession numbers: WP199: MW202336; WP204: MW202335; WP206o: MW202276; WP206r: MW202275).

In this study, the term "haplotype" is used to refer to a unique ITS2 sequence within a species (Lutz et al. 2019). To check the species identity and assignment to the known haplotypes, ITS2 sequences obtained during this study were compared with available records at NCBI using BLAST search. A strict $100 \%$ sequence similarity threshold was applied (i.e. two sequences belong to the same haplotype if they are identical).

\section{Lipid extraction and fatty acid methyl esters analysis (FAMEs)}

Cells were lyophilised for $48 \mathrm{~h}$ and stored frozen at $-80{ }^{\circ} \mathrm{C}$ prior to analysis. The extraction procedure was based on the method of Bligh and Dyer (1959), and elution was done from a Sep-Pak Vac Silica cartridge $35 \mathrm{cc}$ (Waters; $10 \mathrm{~g}$ normal-phase silica) by chloroform (neutral lipids), acetone (glycolipids) and methanol (phospholipids) according to Saunders and Horrocks (1984). All classes of lipids were saponified overnight in $10 \% \mathrm{KOH}$ in methanol at room temperature. The structures of FAMEs were assigned by comparison of Gas Chromatography/Mass Spectrometry retention times and fragmentation patterns with those of calibration standard FAMEs (Supelco, Prague), using methods of Temina et al. (2007) and Dembitsky et al. (1991). Procedures were described in detail at Procházková et al. (2018a).

\section{Pigment analysis}

Cells were lyophilised for $48 \mathrm{~h}$ in darkness, extracted with methyl tert-butyl ether and the carotenoids and chlorophylls analysed by HPLC (Agilent 1200 ChemStation) using a C30 column (YMC Carotenoids) and a diode array detector set at $450 \mathrm{~nm}$ according to Procházková et al. (2019b). The peaks of $c i s$-isomers of astaxanthin were assigned by the shift of the peak absorption maximum to lower wavelengths and the presence of an additional side absorption at approximately $375 \mathrm{~nm}$, compared to the all-trans isomer used for calibration (Sigma Aldrich). Since the true dry mass of the snow algal field samples was not measurable due to impurities like 
cryoconite adhering to the cell walls, chlorophyll- $a$ (chl- $a$ ) content was taken as a reference instead.

\section{Photosynthesis}

In vivo chlorophyll fluorescence parameters of melted field samples were obtained with a pulse-amplitude modulated fluorometer (PAM 2000, HeinzWalz GmbH, Germany) in a 0.6-mL chamber and cooled with an ice bath to approximately $2{ }^{\circ} \mathrm{C}$. To obtain the relative electron transport rates (rETR) and the light saturation point $I_{\mathrm{k}}$, cells were exposed to photon flux densities (PFD) of 5, 9, 34, 67, 104, 201, 366, 622 and $984 \mu \mathrm{mol}$ photons $\mathrm{m}^{-2} \mathrm{~s}^{-1}$ for $30 \mathrm{~s}$ each. Four independent biological replicates were measured. For further details, see Procházková et al. (2018a).

\section{Statistical analyses}

Values of average cells sizes, polyunsaturated fatty acids (PUFAs), content in total fatty acids (FAs), astaxanthin-tochlorophyll- $a$ ratio (astaxanthin-to-chl- $a$ ratio) and relative content of geometrical stereoisomers of cis-astaxanthin (9Z/13Z astaxanthin) to all-trans astaxanthin of S. aurantia were compared with those of $S$. nivaloides using unpaired $t$ test with Welch's correction or the Mann-Whitney test in the programme Prism (GraphPad Software, CA, USA).

\section{Results}

\section{Habitat conditions}

During a field campaign in July 2018, several orange- and red-coloured, seasonal and semi-permanent snowfields were found at high Arctic in Svalbard. They occurred close to the coast and in inland valleys as well (Figs. 1,2). The abiotic parameters of virtually monospecific blooms are summarised in Table 2. Meltwater had neutral or slightly acidic $\mathrm{pH}$; its electrical conductivity was low $\left(<21 \mu \mathrm{S} \mathrm{cm}^{-1}\right)$ and the water content in snowpacks (SWE) ranged between 50 and $60 \%$ at harvest. The regional climatic conditions during the polar summer included an air temperature drop below zero in mid-June $\left(-1{ }^{\circ} \mathrm{C}\right)$ and its peak at the beginning of August $\left(13{ }^{\circ} \mathrm{C}\right)$ (Online Resource 1$)$, the daily air mean temperature varied between 1.3 and $10.9^{\circ} \mathrm{C}$ (Online Resource 2). From mid-June on, it rose above $5{ }^{\circ} \mathrm{C}$.

\section{Maximal population densities and cell morphologies}

Four spots each of red and orange snow were compared. Cell sizes and cell number counts are summarised in Table 2. The maximal population densities of $S$. aurantia ranged from 1.22 to $1.67 \times 10^{5}$ orange spherical cysts $\mathrm{mL}^{-1}$ and ranged from 0.66 to $1.02 \times 10^{5}$ red spherical cysts $\mathrm{mL}^{-1}$ of $S$. nivaloides. The mean cell diameter of $S$. aurantia was $10.7 \pm 2.6 \mu \mathrm{m}($ mean $\pm \mathrm{SD} ; \mathrm{n}=120)$, while it

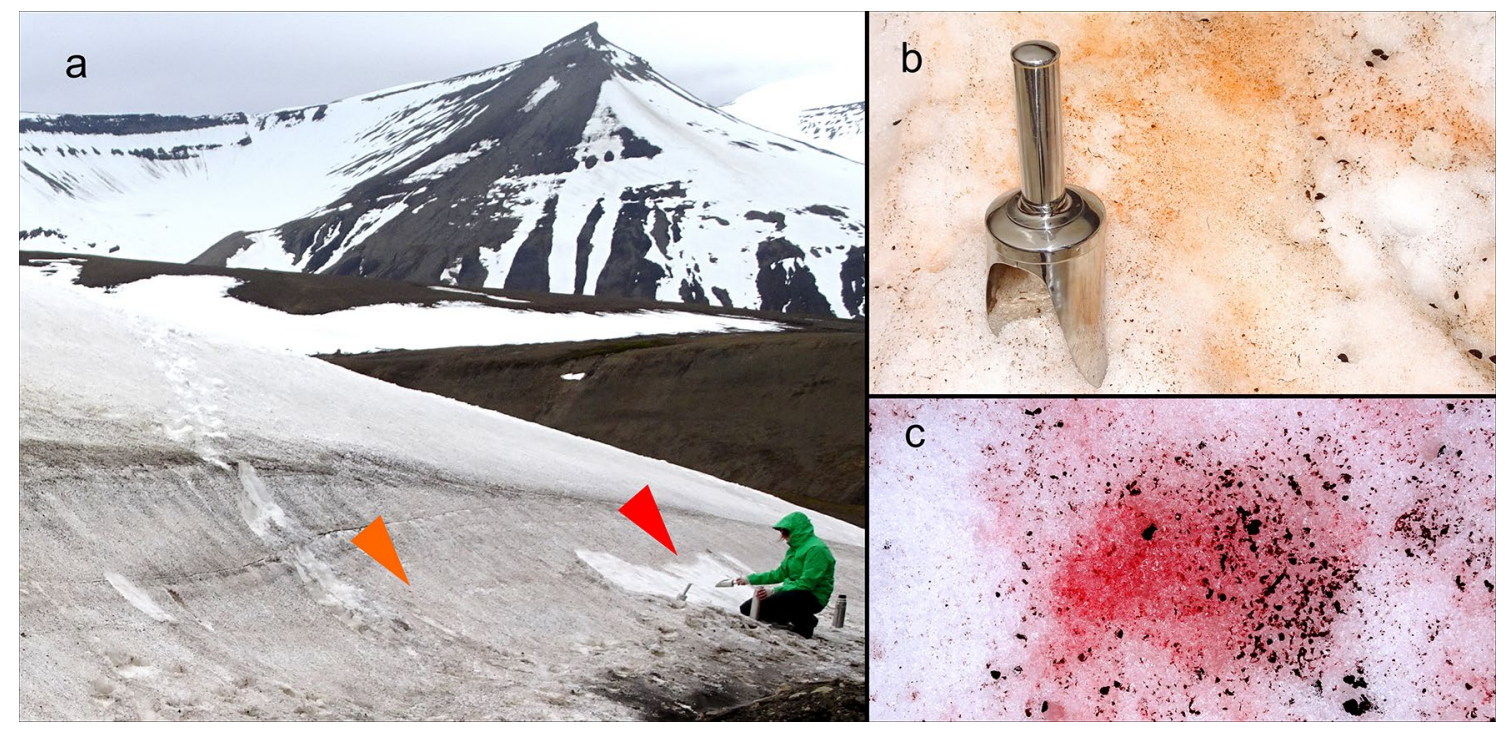

Fig. 2 Overview of a sampling site in Bjørndalen, Spitsbergen, with blooms of Sanguina aurantia and Sanguina nivaloides (a) (samples WP206o, WP206r; bloom colours not visible from distance, marked by orange and red arrow, respectively), blackish colour was caused by snow detritus/cryoconite. Detail view of orange snow (b) caused by $S$. aurantia (sample WP199) and of red snow (c) dominated by $S$. nivaloides (sample WP204) 
Table 2 Abiotic habitat parameters and cyst sizes of Sanguina field samples from Svalbard

\begin{tabular}{lllllll}
\hline Species & Sample & EC & pH & SWE & $\begin{array}{l}\text { Cells per mL } \\
\text { meltwater }\end{array}$ & Cell diameter $(\mu \mathrm{m})$ and size range $(n)$ \\
\hline S. aurantia & WP199 & 9.9 & 7.1 & $60.1 \pm 4.7$ & $167,500 \pm 10,000$ & $10.3 \pm 1.5 ; 7.4-13(30)$ \\
& WP2060 & 20.4 & 6.1 & $56.7 \pm 3.5$ & $122,300 \pm 7400$ & $13.8 \pm 1.4 ; 10.5-16.3(30)$ \\
& MN13 & - & - & - & - & $8.4 \pm 1.3 ; 6-11.9(30)$ \\
& MN21 & - & - & - & - & $10.3 \pm 2.2 ; 6.4-14.3(30)$ \\
S. nivaloides & WP204 & 12 & 7.0 & $59.5 \pm 4.8$ & $66,300 \pm 5000$ & $18.3 \pm 5.2 ; 12.1-37.3(30)$ \\
& WP206r & 7.9 & 6.3 & $52 \pm 3.3$ & $102,450 \pm 6700$ & $14.5 \pm 2.8 ; 9.9-23.2(30)$ \\
& MN1 & - & - & - & - & $21.3 \pm 3.7 ; 14.7-27.8(20)$ \\
& MN22 & - & - & - & - & $20.2 \pm 3.6 . ; 14-33(30)$ \\
\hline
\end{tabular}

Electrical conductivities (EC; $\mu \mathrm{S} \mathrm{cm}{ }^{-1}$ ), $\mathrm{pH}$ of meltwater, the snow water equivalent (SWE; \%), maximum population density \pm standard deviation (SD), average cell sizes $(\mu \mathrm{m})$ and cell size ranges (with $n=$ number of cells measured) are shown was $18.3 \pm 4.7 \mu \mathrm{m}($ mean $\pm \mathrm{SD} ; n=110)$ in $S$. nivaloides (Table 2). The cell sizes of the two species were significantly different (Mann Whitney test, $U=838.5, p<0.0001$ two tailed), and a marginal overlap of the cell size ranges was observed. No motile stages (flagellates) were observed for either species. In young cysts of $S$. aurantia, the cytoplasm contained an irregularly shaped and faint green chloroplast, and no other pigmented structures were present (Fig. 3a). Mature smooth-walled cysts of $S$. aurantia were dominated by orange pigmented lipid bodies (Fig. 3b). In this species, lipid bodies (Fig. 3d) characteristically fused during cyst maturation, resulting in a peripheral network of massive lipid accumulations (Fig. 3b, e). Sanguina aurantia possessed a low number of thylakoid membranes in the stroma of chloroplast lobes, forming loosely arranged layers, and no plastoglobules were visible (Fig. 3c, e). In young cysts of $S$. nivaloides, the parietal chloroplast containing numerous plastoglobules was visible (Fig. $3 \mathrm{~g}$ ). In mature smoothwalled cysts of $S$. nivaloides, lipid bodies fused as well (Fig. 3f, h). Prominent vacuoles containing an osmiophilic crystalline structure were found in both species (shown for S. aurantia, Fig. 3e).

\section{Molecular ITS2 rDNA haplotype identification}

The taxonomical assignment of the samples based on cell morphology of $S$. aurantia and $S$. nivaloides was further confirmed by using the ITS 2 rDNA molecular marker. The orange and red populations (accession numbers in "Material and methods" section) were genetically identical with the most common ITS2 rDNA haplotypes "HA1" and "H1", respectively, as recently established for Sanguina (Procházková et al. 2019a).

\section{Fatty acid composition}

The relative content of FAs (as \% of total fatty acids) in samples of $S$. aurantia $(n=4)$ and $S$. nivaloides cysts $(n=3)$ is given in Fig. 4 (in more detail shown in Online Resource 3). FAs sizes ranged from 14:0 to 23:0. Both species accumulated PUFAs in significantly different quantities (unpaired t test with Welch's correction, Welch corrected $t_{4}=7.006$, $p=0.00222)$, about half in $S$. aurantia $(20.8 \pm 4.6 \%)$ than in S. nivaloides $(47.6 \pm 4.7 \%$ of total lipids; Table 3$)$. The main monounsaturated fatty acid (MUFA) was oleic acid (18:1 (9Z); $19.7 \pm 6.5 \%$ vs. $26.4 \pm 1 \%$ ). The major PUFAs for both species were $\alpha$-linolenic acid $(18: 3$ (9Z, 12Z, 15Z); $6 \pm 3.4 \%$ vs. $14.9 \pm 1.1 \%)$, followed by linoleic acid $(18: 2$ (9Z, 12Z); $5.8 \pm 1 \%$ vs. $14.7 \pm 3.5 \%)$, hexadecatetraenoic acid (16:4 $(4 Z, 7 Z, 10 Z, 13 Z) ; 3.8 \pm 2.3 \%$ vs. $8.8 \pm 2.1 \%)$ and stearidonic acid $(18: 4$ (6Z, 9Z, 12Z, 15Z); $2.7 \pm 2.2 \%$ vs. $5.4 \pm 1.2 \%)$. The most prominent saturated fatty acids (SAFAs) were palmitic (16:0) and stearic acids (18:0).

Neutral lipids predominated over glycolipids and phospholipids in total lipids in S. aurantia and $S$. nivaloides field samples (Table 3). There were no significant qualitative differences in FAs between the three major lipid classes of $S$. nivaloides: PUFAs dominated all glycolipids, phospholipids and neutral lipids. In contrast, saturated FAs strikingly prevailed in the glycolipids and were abundant in phospholipids in S. aurantia (Fig. 5, Online Resource 3).

\section{Pigment composition}

The chlorophyll and carotenoid contents of the two species were compared to understand how the different colours of orange and red snow developed. By far, the most abundant pigment in all samples was the secondary ketocarotenoid astaxanthin, which composed $72 \pm 9.9 \%(n=4)$ and $91.7 \pm 0.9 \%(n=4)$ of all pigments in S. aurantia and $S$. nivaloides, respectively. Depending on the stage within cyst maturation, the field populations had an overall astaxanthin-to-chl- $a$ ratio range from $2: 1-8: 1$ for $S$. aurantia, and 12:1-18:1 for $S$. nivaloides. The astaxanthin-to-chl- $a$ ratio was significantly different between the two species (unpaired t test with Welch's correction, Welch corrected 


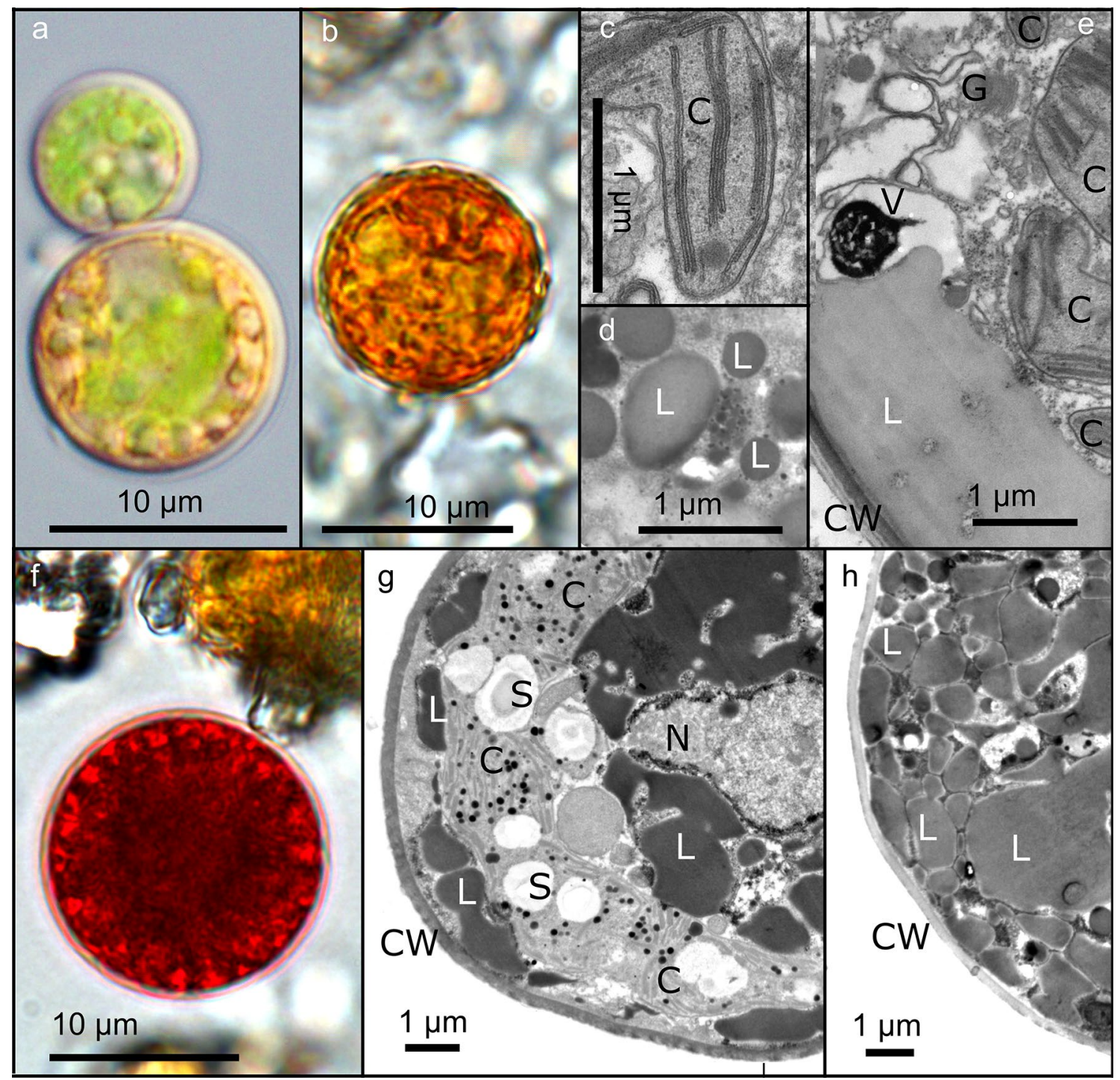

Fig. 3 Light- and transmission electron micrographs of Sanguina aurantia (a-e; sample WP199) and Sanguina nivaloides (f-h; sample WP204) cysts collected in Svalbard. Young cysts with irregularly shaped chloroplast and small lipid bodies $(\mathbf{a}, \mathbf{c}, \mathbf{d}, \mathbf{g})$. Mature cysts

$t_{5}=5.830, p=0.0021$ two tailed). The HPLC chromatograms showed several peaks with identical visible absorption spectra, indicating the presence of astaxanthin derivative-like esters, and the retention times of these peaks were practically identical for both species (data not shown). About $5.4 \pm 0.9 \%$ ( $S$. aurantia; $n=4$ ) and $8.1 \pm 1.2 \%$ (S. nivaloides; $n=4)$, respectively, were recognised as native cis-isomers (likely 13Z) with a shorter wavelength of the absorption maximum and an additional side absorption in the UV range. The relative content of cis-isomers to all-trans astaxanthin was significantly different between the two species (unpaired $\mathrm{t}$ test with Welch's correction, Welch corrected $t_{5}=3.162$, $p=0.0250$ two tailed). Further principal compounds of $S$. aurantia $(n=4)$ and $S$. nivaloides $(n=4)$ were chlorophyll- $a$ with pronounced accumulation of lipid bodies $(\mathbf{b}, \mathbf{e}, \mathbf{f}, \mathbf{h})$. Note cell wall (CW), lipid body (L), starch grain (S) within the chloroplast (C), Golgi body $(\mathrm{G})$, vacuole with electron dense crystalline content (V) and nucleus $(\mathrm{N})$

and $b(23.8 \pm 8 \%$ and $7.3 \pm 0.9 \%$ of all pigments, respectively) and lutein $(5 \pm 2.6 \%$ and $1 \pm 0.4 \%$ of all pigments, respectively). In summary, orange snow contained less red (astaxanthin) but more yellow (lutein) and green compounds (chlorophylls).

\section{Photosynthesis}

The photosynthetic activities of $S$. aurantia and $S$. nivaloides were compared, and rapid light curves were generated (Fig. 6). The values of fluorescence parameters given below are the mean of four independent biological replicates. $S$. aurantia from south-eastern exposed Tverrdalen showed an alpha value of 0.16 , a beta value of -0.012 , a relative 
Fig. 4 Average cellular fatty acid composition of $S$. aurantia $(n=4)$ and $S$. nivaloides $(n=3)$ field samples in $(\%)$ of total fatty acids ( \pm standard deviation). The relative proportion of saturated (SAFA), monounsaturated (MUFA) and polyunsaturated (PUFA) fatty acids ( \pm standard deviation) is given in the inset. The figure shows only fatty acids with abundances greater than $0.2 \%$. A detailed fatty acid profile of all field samples including FAs accounting at least of $0.1 \%$ in total fatty acids is in Online Resource 3

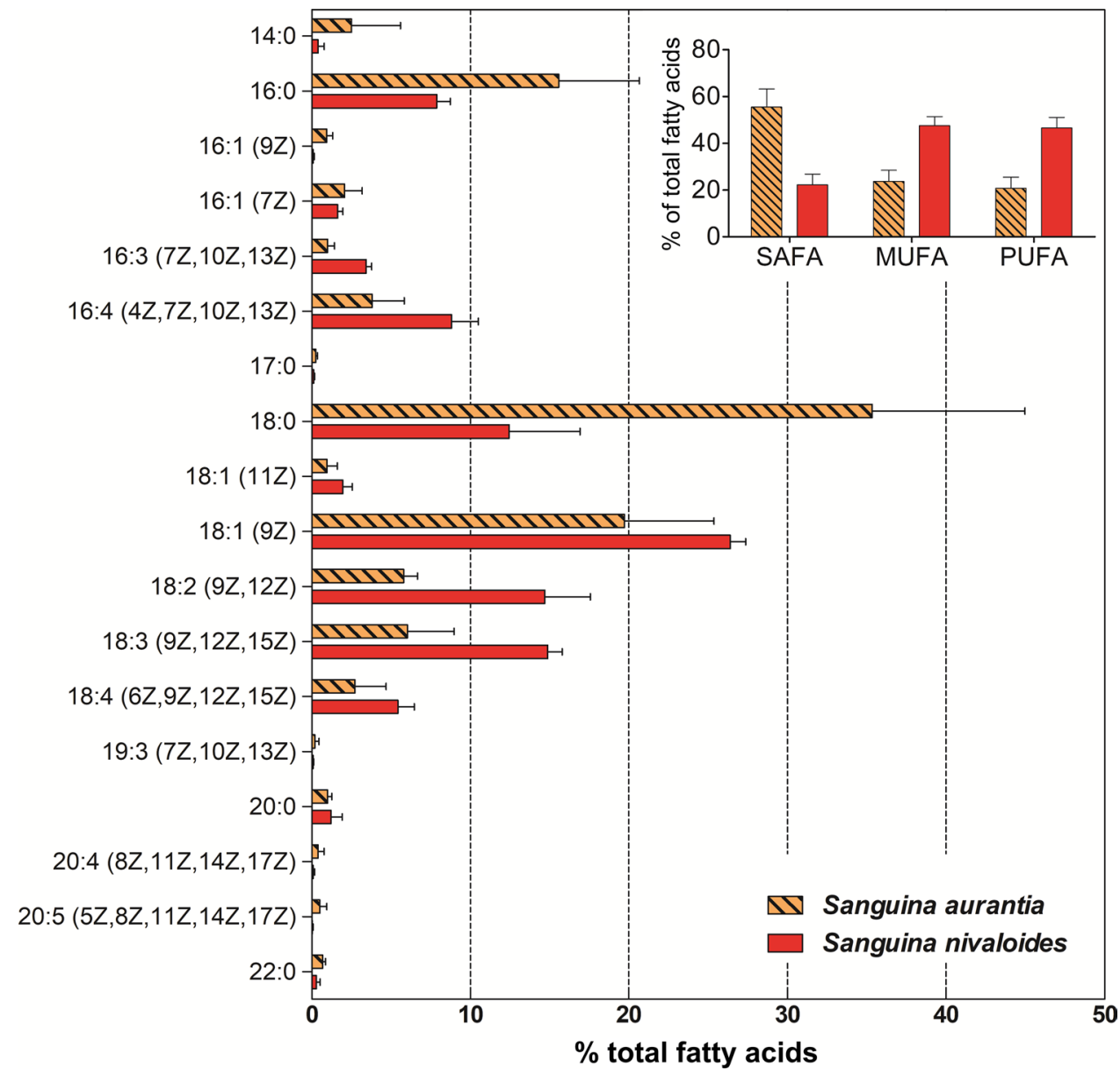

Table 3 Relative amounts of lipid fractions in S. aurantia (WP199) and S. nivaloides (WP204) field cysts

\begin{tabular}{lll}
\hline & Sanguina aurantia & $\begin{array}{l}\text { Sanguina } \\
\text { nivaloides }\end{array}$ \\
\hline Neutral lipids & 55.0 & 72.7 \\
Glycolipids & 28.3 & 15.0 \\
Phospholipids & 16.7 & 12.3 \\
\hline
\end{tabular}

Values are in $(\%)$ of total lipids
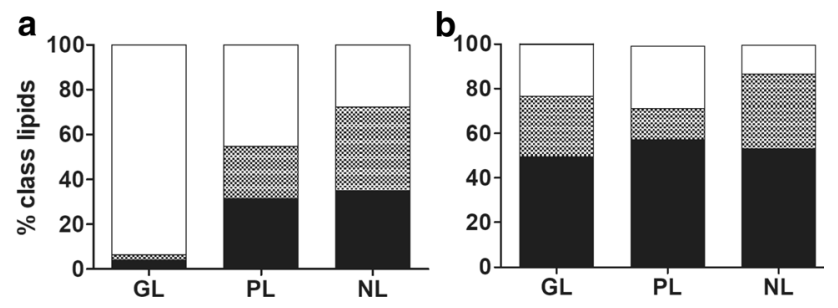

Fig. 5 The relative proportions of saturated (white), monounsaturated (black-white checked) and polyunsaturated fatty acids (black) in Sanguina aurantia (a; sample WP199) and Sanguina nivaloides cysts (b; sample WP204) in the three main lipid classes (GL glycolipids, $P L$ phospholipids, $N L$ neutral lipids)

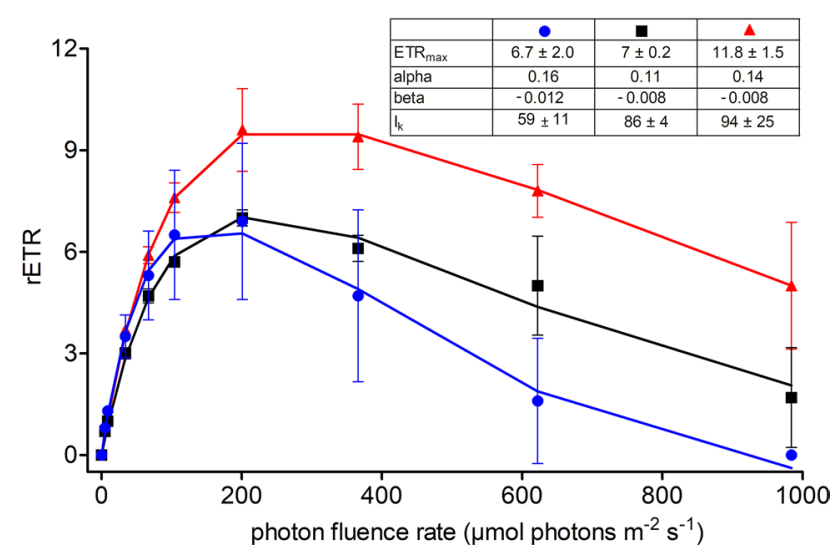

Fig. 6 Comparison of three rapid light curves between field cysts of the two closely related Sanguina species. The effect of increasing photon fluence rates ( $x$-axis) on the relative electron transport rate (rETR; $y$-axis) of chloroplasts are shown for S. aurantia (blue circles, sample WP199) and S. nivaloides (black boxes, sample WP206r; red triangles, sample WP204). Values are means of four independent biological replicates $(n=4, \pm \mathrm{SD})$. The data points were fitted to the photoinhibition model of Walsby (1997) 
ETR $_{\max }$ of $6.7 \pm 2$ and $I_{\mathrm{k}}$ of $59 \pm 11 \mu \mathrm{mol}$ photons $\mathrm{m}^{-1} \mathrm{~s}^{-1}$ $(n=4)$. By contrast, a $S$. nivaloides population occurring in the same valley showed an alpha of 0.14 , a beta of -0.008 , a relative ETR $_{\max }$ of $11.8 \pm 1.5$ and $I_{\mathrm{k}}$ of $94 \pm 25 \mu \mathrm{mol}$ photons $\mathrm{m}^{-2} \mathrm{~s}^{-1}(n=4)$. A population of $S$. nivaloides from a north-western exposure in Bjørndalen exhibited one quarter lower values to the other $S$. nivaloides: an alpha of 0.11 , a relative $\mathrm{ETR}_{\max }$ of $7 \pm 0.2$, while only slightly lower $I_{\mathrm{k}}$ of $86 \pm 4 \mu \mathrm{mol}$ photons $\mathrm{m}^{-2} \mathrm{~s}^{-1}$ and an identical beta of -0.008 $(n=4)$. Thus, the light-dependent photosynthetic rates of $S$. nivaloides from these two sites suffered photoinhibition from medium light intensities (of the measured range) onwards, which was 400 or $200 \mu \mathrm{mol}$ photons $\mathrm{m}^{-2} \mathrm{~s}^{-1}$. S. aurantia showed signs of photoinhibition from $200 \mu$ mol photons $\mathrm{m}^{-2} \mathrm{~s}^{-1}$ on.

\section{Discussion}

\section{Ecology and spatial distribution}

Sanguina aurantia and S. nivaloides thrived in melting summer snow at the same Arctic sites next to each another or alone not only in the same, but also in different valleys. At the scale of a dozen centimetres to a metre, a continuum of solely red or orange patches to occasional mixed spots consisting of the two species was observed, with mixed patches likely as a result of peripheral merging of populations in the course of snow melting (see Supplementary Fig. S2 in Procházková et al. 2019a). Alternatively, the orange cells were part of the macroscopically dark red population or vice versa, likely because "seed banks" of the two species (i.e. remaining cysts from the year before) were situated close to each other. In the metagenomic study of Brown et al. (2016), sun-exposed patches were composed of multiple species, and each species within a patch was highly clonal. It was inferred to be an effect of stochastic (re-)establishment of populations in situ from the previous growing seasons and strong founder or priority effect (i.e. the impact that an organism has on community development due to a sooner arrival at a site). Although is it not known at which point the blooms become macroscopically visible at Svalbard, the last air temperature measured below the freezing point occurred at least 2 weeks prior sampling. The cells reached maximum population densities comparable to those reported earlier from the same archipelago (Müller et al. 1998), namely $10^{4}$ cells $\mathrm{mL}^{-1}$ for either the orange (S. aurantia) or $10^{5}$ cells $\mathrm{mL}^{-1}$ for the red (S. nivaloides) spherical cysts. At lower cell densities (data not shown), snowfields dominated by the latter may appear pinkish (see the edges of the red spot in Fig. 2c). Other snow algae like Chloromonas (C.) spp. were very sparse and did not contribute significantly to these numbers (data not shown). One population in the present study (WP199, Table 1) was located in exactly the same position (identical GPS coordinates) as a sample collected 8 years earlier (Sva 10-8, Procházková et al. 2019a). As already observed in 2010 , orange and red spots were close to each other in 2018. This is an indication that snow algae show a long-term site fidelity in such seasonal snowpacks, and this has been observed for other snow algae as well, e.g. Chlainomonas sp. (Remias et al. 2005; Procházková et al. 2018b). Other concepts including an annual airborne cell circulation have been proposed for persistent snow fields in steep snow slopes of Svalbard (Müller et al. 2001), which would explain a repeated observation of snow blooms year after year at these topographically prominent sites.

\section{Morphology of the cysts}

The range of cell sizes described in the present study was consistent with those given in the initial descriptions of the two species in Procházková et al. (2019a). In this study, young cysts of both species significantly differed in their cytosolic lipid body organisation, fusing sooner during cell maturation into larger, irregularly shaped lipid bodies in $S$. aurantia (Fig. 3e) when compared to $S$. nivaloides. Lower numbers of thylakoid membranes per stroma volume and less thylakoids stacked to each other are a strategy of the highly dynamic photosystem II to respond to high light conditions (e.g. Anderson et al. 1988, 2008). This could explain the faint green colour of the chloroplast in S. aurantia at the light microscope. In contrast, an alpine population of mature red spherical cysts had 3 to 7 thylakoid membranes arranged in a grana-like arrangement in the central chloroplast, which was fully surrounded by abundant astaxanthin lipid bodies (Remias et al. 2005). Moreover, a striking difference was observed by TEM, while $S$. aurantia did not contain plastoglobules in the chloroplasts, these structures were very dominant in $S$. nivaloides chloroplasts, suggesting a different physiological status. Plastoglobules are lipoprotein particles inside the chloroplast accumulating upon high light stress (Austin et al. 2006; Rottet et al. 2015) and were prominently found upon experimental UV-A and UV-B treatments in the freshwater red alga Batrachospermum turfosum (Aigner et al. 2017) and the streptophyte green alga Zygnema sp. (Holzinger et al. 2018).

A convergent cellular adaptation for tolerating excessive irradiances was reported for another, ecologically and taxonomically different extremophilic algal group, the glacial algae: these microorganisms live in a distinct habitat, wet ice surfaces, but not in melting snow, and they are streptophytic algae and thus closer related to land plants than green algae sensu stricto where Sanguina belongs to. The chloroplast of glacial algae is positioned under the shading phenolic pigment and remains practically low-light-adapted despite exposure to full irradiation (Williamson et al. 2020). 
In these two cases, the strategy of protection by secondary pigments was realised by biochemically distinct compounds: the dark phenols of glacier algae are hydrophilic and stored in vacuoles, while the non-polar lipophilic carotenoids of red snow algae are accumulated in lipid bodies. These pigments have significant capabilities in absorbing UV and VIS wavelengths in both cases, despite with some spectral differences (Remias 2012).

\section{Fatty acid composition}

In S. nivaloides, the content of PUFAs was similarly high in all lipid classes, and they were less abundant in $S$. aurantia. These compounds are important for tuning cellular responses and resilience under a range of harmful abiotic conditions and for the adjustment of the photosynthetic apparatus (Kugler et al. 2019). In accordance to this study, such high contents of PUFAs found in Sanguina nivaloides, in particular C18:2, C18:3, C18:4, C16:4 and C16:3, were reported from red snow dominated by the same species (the operation taxonomic unit [OTU] was assigned to "uncultured Chlamydomonadaceae" GU117577-now S. nivaloides in NCBI) in the study of Lutz et al. (2016). Moreover, a similarly high content of PUFAs was observed in red cysts of Chlainomonas and Chloromonas (Procházková et al. 2018b, 2019b), and for vegetative (green) flagellates of Chloromonas (Řezanka et al. 2008). In the present study, Sanguina aurantia accumulated only half the amount of PUFAs in total fatty acids as $S$. nivaloides. However, Spijkerman et al. (2012) reported a high Arctic population of spherical orange cysts harvested in mid-August (i.e. 1 month later than conducted here) to have a very high accumulation of PUFAs comparable with $S$. nivaloides from the same location (compare sample 9/10-1a and 9/10-1b in Spijkerman et al. (2012)), but their data were based on a single measurement. One may hypothesise that either the complete maturation of the cysts of $S$. aurantia takes longer (i.e. to accumulate very high levels of PUFAs), or $S$. aurantia is not a true snow alga sensu Remias (2012) (i.e. it does not reproduce only in meltwater between snow or ice crystals). The former hypothesis may be tested by a later field sampling. The second requires terrestrial sampling outside of snow fields. Both scenarios may partly explain the restricted distribution of S. aurantia in the (Sub-)Arctic climate which are present also in alpine zone of some mid-latitude mountain ranges (Peel et al. 2007). Interestingly, Sanguina lineages exist, which are different to $S$. aurantia, which seem to have a distribution restricted to one of the Earth's poles: "Chlamydomonas"- snow group A sensu Segawa et al. (2018) (a member of a well-supported ITS2 rDNA clade comprising also Sanguina nivaloides GU117577.1) is common in Antarctica but almost absent in the Arctic in the data of Segawa et al. (2018). Investigation of special structuring of genetic diversity enables to document patterns in evolutionary divergence of eukaryotic organisms: some new microalgal lineages were shown to be biogeographically much more differentiated than old ones (Škaloud et al. 2019) while they probably do not differ in terms of possible dissemination.

The dominance of oleic acid 18:1 (9Z) in nutrient depleted laboratory cultures and in field cysts (Spijkerman et al. 2012) during late summer apparently reflects its importance as a precursor in the synthesis of PUFAs (e.g. linoleic and/or $\alpha$-linolenic acids) in all eukaryotic organisms (Gurr 1971; Leya 2013). It means that high production of PUFAs is determined by the presence of oleic acid. Temperature modulates the fatty acid profile in Antarctic ice microalgae (An et al. 2013), and increased unsaturation of the fatty acids in membrane lipids plays a major role in avoiding membrane rigidification at low temperatures (Morgan-Kiss et al. 2006). Moreover, the biosynthetic pathway leading to oleic acid was highly upregulated in a green alga in a response to cold (Hwangbo et al. 2014). Oleic acid is also accumulated in the pre-akinete stages of Zygnema sp. derived from nitrogen depleted cultures or mature field samples (Pichrtová et al. 2016; Arc et al. 2020); therefore, this can be considered as a general strategy observed in phylogenetically distinct streptophytic organisms.

The key factors influencing the qualitative fatty acid composition of lipids are temperature, nutrients, PAR, taxonomic affiliation and the physiological state of an alga (Kumari et al. 2013). Since both bloom types were harvested from almost identical locations, the differences found should reflect species-specific responses (Teoh et al. 2004) or the cell maturity level at the time of harvest rather than sitespecific microhabitat conditions. Interestingly, there is an increasing evidence that some algae isolated from polar habitats (snow, soil, sea water) have broad temperature optima for growth (covering mesophilic conditions), and SAFAs may dominate their FAs regardless of the cultivation temperature (Teoh et al. 2004). In general, molecular mechanisms behind adaptation of polar microalgae can be explored by a variety of "omic" techniques (Lyon and Mock 2014).

\section{Pigments}

The ratio of astaxanthin to chl- $a$, which is primarily responsible for the overall cell colour, was consistent for $S$. aurantia with the reports of small orange cysts in a previous study from Svalbard (Müller et al. 1998). The ratios in S. nivaloides were comparable or slightly lower than those previously reported (21:1 from Wyoming, Bidigare et al. 1993; 18-25:1 in Tyrolean Alps, Remias et al. 2005; 34:1 from Svalbard, sample "a8" of Müller et al. 1998). However, red cells from the early melting season had lower astaxanthinto-chl- $a$ ratios (8:1 in Remias et al. 2005; and in Remias and Lütz 2007). The less intense colour of $S$. aurantia can 
be explained partly by the lower astaxanthin-to-chl- $a$ ratio compared to $S$. nivaloides. Theoretically, the total pigment content could be less as well, but a calculation based on dry mass was not possible, because the harvested samples had cryoconite particles attached to the outer cell wall which precluded accurate weights. A further hypothesis why less intense overall pigmentation was observed in S. aurantia is because the astaxanthin concentration in their lipid bodies should be lower. On the other hand, the observed differences in the relative contents of $c i s$-isomers to all-trans astaxanthin between the two species have no impact on cell pigmentation. The absorption peak shift between cis- and all-trans isomers in the visible range is small ( $468.0 \mathrm{vs} 477.6 \mathrm{~nm}$ ), so that human eye cannot distinguish it (Yuan and Chen 1997). Consequently, the astaxanthin isomers have the same visual red colour. The main absorption differences take place in the UV-A range. The broad ranges of astaxanthin-to-chl- $a$ ratios in samples within both species may be caused by the individual extent of maturation of a population in course of the summer season (e.g. Fig. 3a); however, this should be tested by single-cell metabolomics (Lutz et al. 2015). Also, site-specific factors like exposure to irradiation or the nutrient availability may play a role. However, this was not systematically tested. Since the cysts are metabolically active (as demonstrated by the rapid light curves) but do not divide (cell cleavages of the cysts on the snow surface has never been observed for Sanguina, to our knowledge), their fate is to continue accumulating lipids and astaxanthin until the limit of cellular storage capabilities in lipid bodies. The cisisomer of astaxanthin was detected in a smaller amount in Arctic samples using a C30 HPLC column compared to several high alpine populations of red spherical cysts formerly assigned to "Chlamydomonas nivalis" from the Austrian Alps measured with a different method using a C18 column (Remias and Lütz 2007).

As far as it is known, there are no further species causing orange snow phenomenon in the (Sub-)Arctic than S. aurantia; consequently, this species can be identified by macroscopic observation in these regions, because other snow algae causing a similar snow discoloration, e.g. C. polyptera found next to penguin colonies (Remias et al. 2013), are not known from the northern hemisphere.

\section{Photobiology}

The rapid light curves of field cysts differed between the two studied Sanguina species: the low light saturation point $\left(I_{\mathrm{k}}\right)$ of $S$. aurantia indicated that one third to almost a half of photosynthetic active irradiation (PAR) was sufficient for PS II to become saturated, compared to S. nivaloides. Moreover, as apparent from the higher alpha value, $S$. aurantia was more effective in utilising low light levels. Minor photobiological differences between the two $S$. nivaloides populations may be explained by the exposure of their populations to the different cardinal directions (north-western vs. southeastern exposure of the snowfield) and different maturation level of the cells (i.e. astaxanthin-to-chl- $a$ ratio: WP206r vs. WP204 $=11.9$ vs. 16.3 ).

The first insight into the differences in photobiology between orange and red spherical cysts from Svalbard was reported previously using PAM fluorometry in situ (Stibal et al. 2007). Contrary to these Arctic populations, no photoinhibition was noticed up to high light levels of $2000 \mu \mathrm{mol}$ photons $\mathrm{m}^{-2} \mathrm{~s}^{-1}$, and the alpha was almost twice higher for red spherical cysts from the Austrian Alps (Procházková et al. 2018b) indicating photobiological plasticity of the alpine population at low and high light levels. Since this alpine population was genetically identical to the Arctic one in the ITS2 rDNA molecular marker (haplotype "H1" sensu Procházková et al. 2019a), this finding is indicating an intraspecific flexibility of photosystem II in S. nivaloides in adapting to prevailing local light conditions. A similar phenomenon was observed for another snow alga $C$. hindakii (Procházková et al. 2019b). However, there are no data available yet about photobiology and pigment content of $S$. aurantia populations from mid-latitude mountains in Colorado and Washington States. Indeed, high alpine sites significantly differ from the Arctic/Antarctic ones in ambient maximal PAR irradiances, reaching around noon up to $2500 \mu \mathrm{mol}$ photons $\mathrm{m}^{-2} \mathrm{~s}^{-1}$ in the former (Sommaruga and Psenner 1997; Gorton et al. 2001), while being considerably lower (about $1500 \mu \mathrm{mol} \mathrm{m}^{-2} \mathrm{~s}^{-1}$ ) due to lower light angle and frequent cloud cover in the latter (Stibal et al. 2007; Davey et al. 2019). In proximity to our sampling sites at the glacier Longyearbreen, maximal PAR around noon on a summer sunny day was reported to vary between $\sim 1000$ and $1100 \mu \mathrm{mol} \mathrm{m}^{-2} \mathrm{~s}^{-1}$ (Remias et al. 2012). The rapid light curves of the polar populations of the two Sanguina species indicate shade-adapted photophysiology (higher alpha, relatively low $I_{\mathrm{k}}$, activity decline from medium light levels on) which may reflect local low light conditions at Svalbard. At King George Island (Antarctica), photosynthetic parameters of snow microbial communities were dependent on sampling site, species composition and bloom colour (Soto et al. 2020). Consistently with our study, their orange snow comprising mainly the OTUs assigned to Sanguina spp., uncultured alga OTU 004 and uncultured Chlorella spp. had higher alpha and twice lower $I_{\mathrm{k}}$ when compared to red snow community dominated by Sanguina spp. and C. chenangoensis (Soto et al. 2020).

\section{Conclusion}

This study provided the first ecophysiological comparison of two closely related species causing snow blooms in the Arctic. Although the cysts of $S$. aurantia and S. nivaloides share the same habitats, they significantly differed in cell sizes, 
astaxanthin-to-chlorophyll- $a$ ratios and quantitative fatty acid composition. From a physiological point of view, the restriction of $S$. aurantia to (Sub-)Arctic climates remains unknown but could be attributed to the lower astaxanthin content, leading to less UV absorption capacity compared to the cosmopolitan S. nivaloides. Moreover, the formation of plastoglobules reducing the amount of thylakoid membranes in $S$. nivaloides may contribute to photoprotection.

Acknowledgements Lenka Procházková and Linda Nedbalová acknowledge funding from the Czech Science Foundation (GACR): 18-02634S. Daniel Remias acknowledges funding from the Austrian Science Fund (FWF): P29959. The study was supported by the Ministry of Education, Youth and Sports of the Czech Republic (LM2015078 CzechPolar 2 Czech Polar Research Infrastructure and CZ.02.1.01/0.0 /0.0/16_013/0001708 Ecopolaris) to Josef Elster, University of South Bohemia, Czech Republic. We are grateful to Josef Elster for support in the field and to Tomáš Hájek for technical support (both: University of South Bohemia in České Budějovice, Czech Republic). We acknowledge UNIS (The University Centre in Svalbard) for providing climatic data from automatic weather station in Adventdalen (Svalbard). We thank Cathy Kilroy (National Institute of Water and Atmospheric Research, Christchurch, New Zealand), Ken Ryan (Victoria University of Wellington New Zealand) and an anonymous referee for their fruitful comments that greatly improved the paper.

Author contributions LP and DR designed this study with input from LN. LP and DR jointly collected the field samples. LP was responsible for photosynthesis measurements. LP sequenced the field material. LP and DR conducted independently light microscopy. AH and LP performed transmission electron microscopy independently. Tř was responsible for fatty acid methyl esters analysis. DR carried out the pigment profile analysis. LP wrote the manuscript with the edit and input of DR. Final editing of the manuscript was done by Tř, AH and LN. All authors discussed, read and approved the final manuscript.

Funding Open access funding provided by Austrian Science Fund (FWF).

\section{Compliance with ethical standards}

Conflict of interest The authors declare they have no conflict of interest.

Open Access This article is licensed under a Creative Commons Attribution 4.0 International License, which permits use, sharing, adaptation, distribution and reproduction in any medium or format, as long as you give appropriate credit to the original author(s) and the source, provide a link to the Creative Commons licence, and indicate if changes were made. The images or other third party material in this article are included in the article's Creative Commons licence, unless indicated otherwise in a credit line to the material. If material is not included in the article's Creative Commons licence and your intended use is not permitted by statutory regulation or exceeds the permitted use, you will need to obtain permission directly from the copyright holder. To view a copy of this licence, visit http://creativecommons.org/licenses/by/4.0/.

\section{References}

Aigner A, Holzinger A, Karsten U, Kranner I (2017) The freshwater red alga Batrachospermum turfosum (Florideophyceae) can acclimate to a wide range of temperature and light conditions. Eur J Phycol $52: 238-249$

An M, Mou S, Zhang X, Ye N, Zheng Z, Cao S, Xu D, Fan X, Wang Y, Miao J (2013) Temperature regulates fatty acid desaturases at a transcriptional level and modulates the fatty acid profile in the Antarctic microalga Chlamydomonas sp. ICE-L. Bioresour Technol 134:151-157

Anderson J, Chow W, Goodchild D (1988) Thylakoid membrane organisation in sun/shade acclimation. Aust J Plant Physiol 15:11-26

Anderson JM, Chow WS, De Las RJ (2008) Dynamic flexibility in the structure and function of photosystem II in higher plant thylakoid membranes: the grana enigma. Photosynth Res 98:575-587

Arc E, Pichrtová M, Kranner I, Holzinger A (2020) Pre-akinete formation in Zygnema sp. from polar habitats is associated with metabolite re-arrangement. J Exp Bot 71:3314-3322

Austin JR II, Frost E, Vidi PA, Kessler F, Staehelin LA (2006) Plastoglobules are lipoprotein subcompartments of the chloroplast that are permanently coupled to thylakoid membranes and contain biosynthetic enzymes. Plant Cell 18:1693-1703

Bidigare RR, Ondrusek ME, Kennicutt MC II, Iturriaga R, Harvey HR, Hoham RW, Macko SA (1993) Evidence for a photoprotective function for secondary carotenoids of snow algae. J Phycol 29:427-434

Bligh EG, Dyer WJ (1959) A rapid method of total lipid extraction and purification. Can J Biochem Phys 37:911-917

Brown SP, Tucker AE (2020) Distribution and biogeography of Sanguina snow algae: fine-scale sequence analyses reveal previously unknown population structure. Ecol Evol 10:11352-11361

Brown SP, Ungerer MC, Jumpponen A (2016) A community of clones: snow algae are diverse communities of spatially structured clones. Int J Plant Sci 177:432-439

Davey MP, Norman L, Sterk P, Huete-Ortega M, Bunbury F, Loh BKW, Stockton S, Peck LS, Convey P, Newsham KK, Smith AG (2019) Snow algae communities in Antarctica-metabolic and taxonomic composition. New Phytol 222:1242-1255

Dembitsky VM, Řezanka T, Bychek IA, Shustov MV (1991) Identification of fatty acids from Cladonia lichens. Phytochemistry 30:4015-4018

Gorton HL, Williams WE, Vogelmann TC (2001) The light environment and cellular optics of the snow alga Chlamydomonas nivalis (Bauer) Wille. Photochem Photobiol 73:611-620

Gurr MI (1971) The biosynthesis of polyunsaturated fatty acids in plants. Lipids 6:266-273

Hisakawa N, Quistad SD, Hester ER, Martynova D, Maughan H, Sala E, Gavrilo MV, Rohwer F (2015) Metagenomic and satellite analyses of red snow in the Russian Arctic. PeerJ 2015:e1491

Hoham RW, Remias D (2020) Snow and glacial algae: a review. J Phycol 56:264-282

Holzinger A, Albert A, Aigner S, Uhl J, Schmitt-Kopplin P, Trumhová K, Pichrtová M (2018) Arictic, Antarctic and temperate green algae Zygnema spp. under UV-B stress: vegetative cells perform better than pre-akinetes. Protoplasma 255:1239-1252

Hwangbo K, Ahn JW, Lim JM, Il PY, Liu JR, Jeong WJ (2014) Overexpression of stearoyl-ACP desaturase enhances accumulations of oleic acid in the green alga Chlamydomonas reinhardtii. Plant Biotechnol Rep 8:135-142

Kugler A, Zorin B, Didi-Cohen S, Sibiryak M, Gorelova O, Ismagulova T, Kokabi K, Kumari P, Lukyanov A, Boussiba S, Solovchenko A, Khozin-Goldberg I (2019) Long-chain polyunsaturated fatty acids in the green microalga Lobosphaera incisa 
contribute to tolerance to abiotic stresses. Plant Cell Physiol 60:1205-1223

Kumari P, Kumar M, Reddy CRK, Jha B (2013) Algal lipids, fatty acids and sterols. In: Dominguez H (ed) Functional ingredients from algae for foods and nutraceuticals. Woodhead Publishing, Sawston, pp 87-134

Kvíderová J (2012) Research on cryosestic communities in Svalbard: the snow algae of temporary snowfields in Petuniabukta, Central Svalbard. Czech Polar Rep 2:8-19

Leya T (2013) Snow algae: adaptation strategies to survive on snow and ice. In: Seckbach J, Oren A, Stan-Lotter H (eds) Polyextremophiles. Life under multiple forms of stress. Springer, Dordrecht, pp 401-423

Leya T, Müller T, Ling HU, Fuhr GR (2004) Snow algae from NorthWestern Spitsbergen (Svalbard). In: Wiencke C (ed) The coastal ecosystem of Kongsfjorden, Svalbard: synopsis of biological research performed at the Koldewey Station in the years 19912003 (Berichte zur Polar- und Meeresforschung 492). Bremerhaven, pp 46-54

Lutz S, Anesio AM, Field K, Benning LG (2015) Integrated "omics", targeted metabolite and single-cell analyses of arctic snow algae functionality and adaptability. Front Microbiol 6:1323

Lutz S, Anesio AM, Raiswell R, Edwards A, Newton RJ, Gill F, Benning LG (2016) The biogeography of red snow microbiomes and their role in melting arctic glaciers. Nat Commun 7:11968

Lutz S, Procházková L, Benning LG, Nedbalová L, Remias D (2019) Evaluating amplicon high-throughput sequencing data of microalgae living in melting snow: improvements and limitations. Fottea 19:115-131

Lyon B, Mock T (2014) Polar microalgae: new approaches towards understanding adaptations to an extreme and changing environment. Biology 3:56-80

Morgan-Kiss RM, Priscu JC, Pocock T, Gudynaite-Savitch L, Huner NPA (2006) Adaptation and acclimation of photosynthetic microorganisms to permanently cold environments. Microbiol Mol Biol R 70:222-252

Müller T, Bleiß W, Rogaschewski C-DMS, Fuhr G (1998) Snow algae from northwest Svalbard: their identification, distribution, pigment and nutrient content. Polar Biol 20:14-32

Müller T, Leya T, Fuhr G (2001) Persistent snow algal fields in Spitsbergen: field observations and a hypothesis about the annual cell circulation. Arct Antarct Alp Res 33:42-51

Peel MC, Finlayson BL, McMahon TA (2007) Updated world map of the Köppen-Geiger climate classification. Hydrol Earth Syst Sci Disc 4:439-473

Pichrtová M, Arc E, Stöggl W, Kranner I, Hájek T, Hackl H, Holzinger A (2016) Formation of lipid bodies and changes in fatty acid composition upon pre-akinete formation in Arctic and Antarctic Zygnema (Zygnematophyceae, Streptophyta) strains. FEMS Microbiol Ecol 92:096

Piercey-Normore MD, DePriest PT (2001) Algal switching among lichen symbioses. Am J Bot 88:1490-1498

Procházková L, Remias D, Řezanka T, Nedbalová L (2018a) Chloromonas nivalis subsp. tatrae, subsp. nov. (Chlamydomonadales, Chlorophyta): re-examination of a snow alga from the High Tatra Mountains (Slovakia). Fottea 18:1-18

Procházková L, Remias D, Holzinger A, Řezanka T, Nedbalová L (2018b) Ecophysiological and morphological comparison of two populations of Chlainomonas sp. (Chlorophyta) causing red snow on ice-covered lakes in the High Tatras and Austrian Alps. Eur J Phycol 53:230-243

Procházková L, Leya T, Křížková H, Nedbalová L (2019a) Sanguina nivaloides and Sanguina aurantia gen. et spp. nov. (Chlorophyta): the taxonomy, phylogeny, biogeography and ecology of two newly recognised algae causing red and orange snow. FEMS Microbiol Ecol 95:064
Procházková L, Remias D, Řezanka T, Nedbalová L (2019b) Ecophysiology of Chloromonas hindakii sp. nov. (Chlorophyceae), causing orange snow blooms at different light conditions. Microorganisms 7:434

Remias D (2012) Cell structure and physiology of alpine snow and ice algae. In: Lütz C (ed) Plants in alpine regions. Cell physiology of adaption and survival strategies. Springer, Wien, pp 175-186

Remias D, Lütz C (2007) Characterisation of esterified secondary carotenoids and of their isomers in green algae: a HPLC approach. Algol Stud 124:85-94

Remias D, Lütz-Meindl U, Lütz C (2005) Photosynthesis, pigments and ultrastructure of the alpine snow alga Chlamydomonas nivalis. Eur J Phycol 40:259-268

Remias D, Holzinger A, Aigner S, Lütz C (2012) Ecophysiology and ultrastructure of Ancylonema nordenskiöldii (Zygnematales, Streptophyta), causing brown ice on glaciers in Svalbard (high arctic). Polar Biol 35:899-908

Remias D, Wastian H, Lütz C, Leya T (2013) Insights into the biology and phylogeny of Chloromonas polyptera (Chlorophyta), an alga causing orange snow in Maritime Antarctica. Antarct Sci 25:648-656

Řezanka T, Nedbalová L, Sigler K (2008) Unusual medium-chain polyunsaturated fatty acids from the snow alga Chloromonas brevispina. Microb Res 163:373-379

Rottet S, Besagni C, Kessler F (2015) The role of plastoglobules in thylakoid lipid remodeling during plant development. Biochim Biophys Acta Bioenerg 1847:889-899

Saunders RD, Horrocks LA (1984) Simultaneous extraction and preparation for high-performance liquid chromatography of prostaglandins and phospholipids. Anal Biochem 143:71-75

Segawa T, Matsuzaki R, Takeuchi N, Akiyoshi A, Navarro F, Sugiyama S, Yonezawa T, Mori H (2018) Bipolar dispersal of red-snow algae. Nat Commun 9:3094

Škaloud P, Škaloudová M, Doskočilová P, Kim JI, Shin W, Dvořák P (2019) Speciation in protists: spatial and ecological divergence processes cause rapid species diversification in a freshwater chrysophyte. Mol Ecol 28:1084-1095

Sommaruga R, Psenner R (1997) Ultraviolet radiation in a high mountain lake of the Austrian Alps: air and underwater measurements. Photochem Photobiol 65:957-963

Soto DF, Fuentes R, Huovinen P, Gómez I (2020) Microbial composition and photosynthesis in Antarctic snow algae communities: Integrating metabarcoding and pulse amplitude modulation fluorometry. Algal Res 45:101738

Spijkerman E, Wacker A, Weithoff G, Leya T (2012) Elemental and fatty acid composition of snow algae in Arctic habitats. Front Microbiol $3: 1-15$

Stibal M, Elster J, Šabacká M, Kaštovská K (2007) Seasonal and diel changes in photosynthetic activity of the snow alga Chlamydomonas nivalis (Chlorophyceae) from Svalbard determined by pulse amplitude modulation fluorometry. FEMS Microbiol Ecol 59:265-273

Stibal M, Bradley JA, Edwards A, Hotaling S, Zawierucha K, Rosvold J, Lutz S, Cameron KA, Mikucki JA, Kohler TJ, Šabacká M, Anesio AM (2020) Glacial ecosystems are essential to understanding biodiversity responses to glacier retreat. Nat Ecol Evol 4(5):686-687

Temina M, Rezanková H, Rezanka T, Dembitsky VM (2007) Diversity of the fatty acids of the Nostoc species and their statistical analysis. Microbiol Res 162:308-321

Teoh ML, Chu WL, Marchant H, Phang SM (2004) Influence of culture temperature on the growth, biochemical composition and fatty acid profiles of six Antarctic microalgae. J Appl Phycol 16:421-430

Walsby AE (1997) Modelling the daily integral of photosynthesis by phytoplankton: its dependence on the mean depth of the population. Hydrobiologia 349:65-74

White TJ, Bruns T, Lee S, Taylor J (1990) Amplification and direct sequencing of fungal ribosomal RNA genes for phylogenetics. In: Innis MA, Gelfand DH, Sninsky JJ, White TJ (eds) PCR 
protocols - a guide to methods and applications. Academic Press, London, pp 315-322

Williamson CJ, Cook J, Tedstone A, Yallop M, McCutcheon J, Poniecka E, Campbellf D, Irvine-Fynnb T, McQuaidd J, Trantera M, Perkinse R, Anesio A (2020) Algal photophysiology drives darkening and melt of the Greenland Ice Sheet. P Natl Acad Sci USA 117:5694-5705

Yuan JP, Chen F (1997) Identification of astaxanthin isomers in Haematococcus lacustris by HPLC-photodiode array detection. Biotechnol Tech 11:455-459
Publisher's Note Springer Nature remains neutral with regard to jurisdictional claims in published maps and institutional affiliations. 